\title{
Mutation analysis of the spastin gene (SPG4) in patients with hereditary spastic paraparesis
}

\author{
J C Lindsey, M E Lusher, C J McDermott, K D White, E Reid, D C Rubinsztein, \\ R Bashir, J Hazan, P J Shaw, K M D Bushby
}

Human Molecular Genetics Unit, School of Biochemistry and

Genetics, University of Newcastle upon Tyne, Newcastle upon Tyne

NE2 4AA, UK

$\mathrm{J}$ C Lindsey

M E Lusher

K M D Bushby

Department of Neurology, Royal Victoria Infirmary,

Newcastle upon Tyne, UK

C J McDermott

P J Shaw

Department of

Neurology, Royal

Manchester Children's

Hospital, Manchester,

UK

K D White

Department of Medical Genetics,

Wellcome Trust Centre

for the Study of

Molecular

Mechanisms in

Disease,

Wellcome/MRC

Building,

Addenbrooke's

Hospital, Cambridge,

UK

E Reid

D C Rubinsztein

Department of

Biological Sciences,

University of Durham,

Durham, UK

R Bashir

Department of

Developmental

Biology, King's

College, London, UK

J Hazan

Correspondence to:

Dr Bushby,

kate.bushby@ncl.ac.uk

Revised version received 10 May 2000

Accepted for publication 20 June 2000

\begin{abstract}
Background-Hereditary spastic paraparesis is a genetically heterogeneous condition. Recently, mutations in the spastin gene were reported in families linked to the common SPG4 locus on chromosome 2p21-22.

Objectives-To study a population of patients with hereditary spastic paraparesis for mutations in the spastin gene (SPG4) on chromosome 2p21-22.

Methods-DNA from 32 patients (12 from families known to be linked to SPG4) was analysed for mutations in the spastin gene by single strand conformational polymorphism analysis and sequencing. All patients were also examined clinically.

Results-Thirteen SPG4 mutations were identified, 11 of which are novel. These mutations include missense, nonsense, frameshift, and splice site mutations, the majority of which affect the AAA cassette. We also describe a nucleotide substitution outside this conserved region which appears to behave as a recessive mutation.

Conclusions-Recurrent mutations in the spastin gene are uncommon. This reduces the ease of mutation detection as a part of the diagnostic work up of patients with hereditary spastic paraparesis. Our findings have important implications for the presumed function of spastin and schemes for mutation detection in HSP patients. (F Med Genet 2000;37:759-765)
\end{abstract}

Keywords: spastin; hereditary spastic paraparesis; mutation; recessive

Hereditary spastic paraparesis (HSP) comprises a group of inherited neurodegenerative disorders. The defining clinical feature is progressive lower limb weakness and spasticity, with a common pathological feature being degeneration of the corticospinal tracts. ${ }^{1-3}$ HSP is genetically heterogeneous. Autosomal dominant, autosomal recessive, and $\mathrm{X}$ linked inheritance has been described with 13 published loci to date, ${ }^{4-16}$ the commonest mode of inheritance being autosomal dominant.

The genes for only four of these loci have been identified. The two $\mathrm{X}$ linked forms at SPG1 and SPG2 (rare forms of HSP where the disease is allelic with other complex neurological conditions) are the result of mutations in the genes for the $\mathrm{L} 1$ cell adhesion molecule and the proteolipid protein, respectively. ${ }^{4} \mathrm{~A}$ recessive form of the disease linked to chromosome $16 \mathrm{q} 24.3$ (SPG7) is caused by mutations in the gene for paraplegin, ${ }^{17}$ a mitochondrial metalloprotease belonging to the AAA protein family (ATPases associated with a variety of cellular functions)..$^{18}$

Recently, mutations in a novel protein, spastin, have been described in seven families with ADHSP linked to the SPG4 locus on chromosome $2 \mathrm{p} 21-22 . .^{19}$ The majority of families with dominantly inherited HSP $(40-60 \%)^{21} 22$ show linkage to this locus. Spastin, like paraplegin, belongs to the AAA protein family, although these two proteins share little homology outside the AAA motif. Unlike paraplegin which is a mitochondrial protein, spastin has been proposed to have a nuclear localisation. Little is known about the function of spastin although it is highly homologous to the $26 \mathrm{~S}$ proteosome subunit and may participate in the assembly or function of protein complexes. ${ }^{19}$ In this paper we report 13 mutations in the gene for spastin, including one which is present homozygously.

\section{Methods}

A total of 32 unrelated British patients with HSP were involved in this study. Twelve were affected members of families where linkage to the SPG4 locus had previously been shown and the remainder were either from families where the disease showed an autosomal dominant mode of inheritance, but which were too small for linkage analysis, or were the only known case in their family. At least one affected member of each family was examined and a detailed neurological history taken by one of the authors (CMD, KW, ER).

DNA extraction from whole blood was carried out using standard procedures. Primers were designed for mutation detection by single strand conformational polymorphism (SSCP) analysis of the 17 exons of the SPG4 gene using the spastin cDNA sequence (GenBank accession AJ246001) and the genomic sequence (Genbank accession AJ246003). ${ }^{19}$ The sequences of the primers are shown in table 1 .

PCR was performed using the annealing temperatures for the primers shown in table 1. SSCP was performed on two types of gels: $50 \%$ $\mathrm{MDE}^{\mathrm{TM}}$ (Flowgen) and $5 \%$ glycerol gels in $0.6 \% \mathrm{TBE}$ and $8 \%$ polyacrylamide (49:1 acrylamide:bisacrylamide) gels in $0.6 \% \mathrm{TBE}$. The latter type of gel did not allow the detection of any changes than were not seen on the MDE gel, but this gel was better at separating the products of exon $1 \mathrm{a}$ and $1 \mathrm{~b}$ amplification. PCR products showing SSCP changes were sequenced directly on an ABI377 DNA Sequencer. In addition, some changes were 
Table 1 Sequences of the primers

\begin{tabular}{|c|c|c|c|c|}
\hline Exon & Forward primer & Reverse primer & $\begin{array}{l}\text { Product } \\
\text { size (bp) }\end{array}$ & $\begin{array}{l}\text { Annealing } \\
\text { temp }\left({ }^{\circ} \mathrm{C}\right)\end{array}$ \\
\hline 1a & GCCCCCGCCGTAGCAGT & ACGAAGAGGAGCCCCAGGTG & 318 & $62^{\star}$ \\
\hline $1 \mathrm{~b}$ & TACTATTTCTCCTACCCGCTGTTT & CGACCCCACCGCCTTCT & 321 & $57^{\star}$ \\
\hline $1 \mathrm{c}$ & CGGCGGCGGCAGTGAGAG & ATGAGGGCGCGGGAGAAG & 284 & $62^{\star}$ \\
\hline 2 & TTTTTATGTATTACСТСТCAAC & TGGGATGGCTATAAACAAAT & 204 & 55 \\
\hline 3 & TTAGTTGGGAAATGTAGAT & TATGTTAAAAAGCCTGGAC & 246 & 55 \\
\hline 4 & TTTTTACСTTCTCTGTTG & AAGCTTTATTATTTTATGTTAGTT & 156 & 55 \\
\hline 5 & GTTCAGCTACAATTTTCTAATCAC & TATGATCAACTTAAGCAGGAAT & 321 & 55 \\
\hline 6 & ATGTTAGGTTGTATTTTCA & CAAGGTATTTATTATCTATTTCAC & 273 & 55 \\
\hline 7 & TCATAGGGCTTAGGCTTCA & ATGGATTCAGTAACAGATGGTATT & 224 & 55 \\
\hline 8 & CTGTTTGGGAAGATGCT & CTCAAGGACAAGATAAAGTT & 261 & 60 \\
\hline 9 & TGGCCTCATAGCTTACATTTTTAG & ATACGACAATATTGGAAACAGAG & 220 & 55 \\
\hline 10 & GTGCTAGATTTTCAACATA & GCССТTCTTTAAAACTTCTTCC & 270 & 55 \\
\hline 11 & GAATTTAGTAGGACCCACT & GCCACATTAAAAATATCATA & 230 & 55 \\
\hline 12 & ATGGCCAAGGTTAAAAATACAA & CTGGAAGAAAATAGTGAAT & 281 & 55 \\
\hline 13 & CTTTTCCTGTCATTTGCTGTTT & GATGGTAGTTCTTGTTTCTGCTCT & 173 & 55 \\
\hline 14 & ATCATTAATTCTGAAATTAG & ATAAACCAAATCCAAA & 154 & 48 \\
\hline 15 & AAAAAGCGGGAGGGGAAATA & TGGGCAACAGAGTGAGACC & 248 & $56^{\star}$ \\
\hline 16 & TGTATGTATTTTTAAGTGCCTGAC & TTACAATATAGAAGACAAAGAAA & 125 & 55 \\
\hline 17 & AACAGCAGCATCATTACTTT & GTTCTGCAGGTTTACAA & 241 & 55 \\
\hline
\end{tabular}

${ }^{\star}$ Requires the addition of $2 \mathrm{~mol} / \mathrm{l}$ Betaine (Sigma) to the PCR reaction.

confirmed by cloning into pGemTeasy (Promega) and sequenced. For each SSCP change detected in the patients, 100 normal chromosomes were screened under the same conditions.

\section{Results}

Mutations in the SPG4 gene were found in 14 families, nine of whom were already known to be linked to the SPG4 locus.

CLINICAL EXAMINATION OF PATIENTS

At least one affected member of each family was examined. A synopsis of the major points in the history of each family in whom a spastin mutation was identified is detailed below in the order in which the results are presented in table 2. The clinical features for each family are summarised in table 3. Clinical features for families C5, C7, C22, C24, C25, and C27 have been described in more detail previously. ${ }^{22}$

\section{N35}

The single patient examined in this family was the only member of his family (in preceding or subsequent generations, including his three children and 11 grandchildren) with any neurological symptoms at all. He had two sibs, one of whom died at the age of 39 years from myocardial infarction and the other at the age of 81 years of "old age". Neither had had any mobility problems. He was never able to run, but was otherwise asymptomatic until the age of 60 years when he began to notice slowness of his gait and stiffness of his lower limbs with a tendency to trip and difficulty climbing hills. These symptoms progressed slowly, but he remained ambulant at the age of 75 years. On neurological examination, he had mild pes cavus, an exaggerated lumbar lordosis, and a symmetrical, moderately severe spastic paraparesis with mild impairment of vibration sense in the lower limbs. A mild degree of urinary hesitancy was reported, but the upper limbs were normal.

C24

Clinical information was available for seven affected members from two generations of this family, all of whom had typical clinical features of pure spastic paraplegia. Age at onset of symptoms ranged from 2 to 33 years. Three family members used a walking stick and one, symptomatic for 30 years, used a wheelchair. One family member had bladder involvement, one family member suffered from constipation, and another from faecal urgency. The rate of disease progression was variable, though tended to be slow. Three patients had upper limb hyperreflexia. Three subjects had pes

Table 2 Novel mutations detected in the spastin gene

\begin{tabular}{|c|c|c|c|c|c|c|}
\hline Family & $\begin{array}{l}\text { No of affected patients } \\
\text { examined in family }\end{array}$ & $\begin{array}{l}\text { Average age of } \\
\text { onset of disease } \\
\text { (range) }\end{array}$ & Mutation & Exon/intron & Nucleotide change & Protein change \\
\hline N35 & 1 & 60 & $\begin{array}{l}\text { Missense (present } \\
\text { homozygously) }\end{array}$ & Exon 1 & $256 \mathrm{C}>\mathrm{T}$ & S44L \\
\hline $\mathrm{C} 24$ & 7 & $2-33$ & Frameshift & Exon 1 & $411 \mathrm{delG}$ & $\begin{array}{l}\text { Frameshift aa96-159 } \\
\text { 160Stopcodon }\end{array}$ \\
\hline N4 & 5 & $26.2(<5-37)$ & Nonsense & Exon 5 & $859 \mathrm{C}>\mathrm{G}$ & S245Stopcodon \\
\hline N5 & 11 & $28.1(1-50)$ & Nonsense & Exon 5 & $859 \mathrm{C}>\mathrm{G}$ & S245Stopcodon \\
\hline N3 & $\begin{array}{l}1 \text { ( } 2 \text { others affected } \\
\text { but not examined) }\end{array}$ & $3(2-5)$ & Splice & Intron 8 & $1298+1 \mathrm{~g}>\mathrm{a}$ & Presumed missplicing (skipping of exon 8) \\
\hline $\mathrm{N} 2$ & 5 & $11.7(1.5-20)$ & Missense & Exon 10 & $1395 \mathrm{~A}>\mathrm{G}$ & R424G \\
\hline $\mathrm{C} 27$ & 9 & $20.3(<10-27)$ & Frameshift/nonsense & Exon 10 & 1406delT & $\begin{array}{l}\text { Frameshift aa427-436 } \\
\text { 437Stopcodon }\end{array}$ \\
\hline C5 & 8 & $31.4(<5-50)$ & Splice & Intron 11 & $1538+3 a>c$ & Presumed missplicing (skipping of exon 11) \\
\hline N36 & 1 (6 not seen) & $40(-)$ & Splice & Intron 11 & $1538+3-6 \mathrm{del}$ (aagt) & Presumed missplicing (skipping of exon 11) \\
\hline C7 & 6 & $21.4(<2-33)$ & Splice & Intron 12 & $1618+2 t>a$ & Presumed missplicing (skipping of exon 12) \\
\hline $\mathrm{C} 22$ & 5 & $18.5(<2-30)$ & Splice & Intron 13 & $1661+2 t>c$ & Presumed missplicing (skipping of exon 13) \\
\hline N37 & 1 & $11(-)$ & Splice & Intron 15 & $1812+2 t>g$ & Presumed missplicing (skipping of exon 15) \\
\hline $\mathrm{C} 25$ & 11 & $26.4(15-41)$ & Splice & Intron 16 & $1853+2 t>c$ & Presumed missplicing (skipping of exon 16) \\
\hline N8 & 3 & $40(40-40)$ & Missense & Exon 17 & $1875 \mathrm{G}>\mathrm{C}$ & $\mathrm{D} 584 \mathrm{H}$ \\
\hline
\end{tabular}


cavus, two had mild to moderate distal limb amyotrophy, and two had altered lower limb vibration sensation. No family members had overt cognitive impairment.

N4

Five affected family members have been seen in this family, between 12 and 70 years of age. Onset in the youngest child was before the age of 5 years, but in the older family members ranged from 20 to 37 years. With the exception of one female family member, now in her late 30 s, who has needed a wheelchair within three years of diagnosis, the progression has been very slow. Upper limb involvement is minimal (brisk reflexes only in 4/5 members), three have bladder involvement, and the findings in the lower limbs are of a pure spastic paraparesis without wasting or sensory changes. No cognitive changes are reported in any family members.

\section{N5}

Eleven affected subjects are known in this large family, ranging in age from 27 to 72 . Two of the younger family members were reported as having symptoms by the age of 5 years. The onset in the older family members was between 20 and 50 years. One obligate gene carrier remains asymptomatic at 38 years. Three subjects are wheelchair users, all after at least 15 years of symptoms. As with family N4 (now known to have the same mutation, see above), all findings were consistent with a pure hereditary spastic paraplegia, with no cognitive problems, though one person was said to have a paranoid affective disorder.

A necropsy was carried out on one member of this family and the findings were entirely consistent with pure HSP, showing pathology limited to the corticospinal tracts. Myelin pallor and loss of axons was especially pronounced in the lateral and ventral corticospinal tracts. Myelin loss in the dorsal column was most prominent in the cervical spinal cord, but the corticospinal pathways in the cerebral peduncle were well preserved.
N3

Relatively little information is available on this family. However, reported onset in all subjects where this was recorded was before the age of 5 years. One person requires a wheelchair.

\section{N2}

This family has been reported previously. ${ }^{23}$ Onset in the youngest generation was in the first two years of life and in the late teens in previous generations. In all but one family member, the phenotype was consistent with pure HSP. However, one of the older family members had a history of progressive cognitive decline in the two years before his death. Necropsy showed diffuse tau related cortical changes. Another affected family member had a cognitive problem with generalised impairment of verbal learning, non-verbal learning, and memory, detected as learning problems in childhood. The relevance of these difficulties to her HSP is not known.

\section{C27}

Nine affected members from three generations of this family were examined. Age at onset of symptoms ranged from 10 years to 29 years. Two clinically affected subjects were asymptomatic aged 23 and 25 years. Rate of disease progression was variable, although tended to be slow. One subject required a walking stick and three, all symptomatic for more than 30 years, used a wheelchair. Five patients had bladder involvement and three of these required a urinary catheter. Three patients suffered from constipation and two of the male subjects were impotent. Six subjects had upper limb hyperreflexia. Lower limb examination showed signs typical of spastic paraparesis in all cases. Six subjects had foot deformity, one had mild distal lower limb wasting, and three had absent lower limb vibration sensation. No family members had overt cognitive impairment.

\section{C5}

Eight affected members from three generations were examined. Age at onset of symptoms ranged from 5 to 50 years and one affected family member was asymptomatic at the age of 28 years. Two family members required a

Table 3 Clinical features observed in families with spastin gene mutations

\begin{tabular}{|c|c|c|c|c|c|c|c|c|c|c|c|}
\hline Family & $\begin{array}{l}\text { No of } \\
\text { affected }\end{array}$ & $\begin{array}{l}m A A O \\
\text { (range) }\end{array}$ & & $\begin{array}{l}\text { use of } \\
\text { elchair }\end{array}$ & $\begin{array}{l}\text { Vibration } \\
\text { sense }\end{array}$ & $\begin{array}{l}\text { Bladder } \\
\text { disturbance }\end{array}$ & Pes cavus & $\begin{array}{l}\text { Distal } \\
\text { amyotrophy }\end{array}$ & $\begin{array}{l}\text { Upper limb } \\
\text { hyperreflexia }\end{array}$ & Cognition & Other comments \\
\hline N35 & 1 & 60 & 0 & 0 & 1 & 1 & 1 & 0 & 0 & 0 & Lumbar lordosis \\
\hline $\mathrm{C} 24$ & 7 & $23.7(2-33)$ & 3 & 1 & 2 & 1 & 3 & 2 & 3 & 0 & Slow steady progression \\
\hline N4 & 5 & $26.2(5-37)$ & 1 & 0 & 0 & 3 & 1 & 0 & 4 & 0 & \\
\hline N5 & 11 & $28.1(1-50)$ & 1 & 3 & 4 & 8 & 4 & 4 & 11 & 0 & \\
\hline N3 & 3 & $3(2-5)$ & 0 & 1 & - & - & 1 & - & - & - & Incomplete clinical details \\
\hline N2 & 5 & $10.6(1-18)$ & 1 & 2 & 1 & 2 & 0 & 1 & 2 & 2 & $\begin{array}{l}\text { Unusual "tauopathy" described at } \\
\text { necropsy }\end{array}$ \\
\hline C27 & 9 & $20.3(10-29)$ & 1 & 3 & 2 & 5 & 6 & 1 & 6 & 0 & \\
\hline C5 & 8 & $31.4(5-50)$ & 2 & 1 & 5 & 3 & 5 & 2 & 4 & 0 & Choroideremia in 3 \\
\hline N36 & 5 & 40 & 0 & 0 & 1 & 1 & 0 & 1 & 0 & 1 & $\begin{array}{l}\text { Only one clinically evaluated, } \\
\text { complicated by TB and polio as child. }\end{array}$ \\
\hline $\mathrm{C} 7$ & 6 & $21.4(2-37)$ & 1 & 2 & 1 & 3 & 1 & 0 & 5 & 0 & \\
\hline $\mathrm{C} 22$ & 5 & $18.5(2-30)$ & 1 & 0 & 2 & 3 & 3 & 0 & 1 & 0 & 2 with impaired fine touch \\
\hline N37 & 1 & 11 & 0 & 0 & 1 & 0 & 0 & 0 & 1 & 0 & \\
\hline $\mathrm{C} 25$ & 11 & $26.4(15-41)$ & 4 & 5 & 7 & 5 & 6 & 3 & 2 & 0 & $\begin{array}{l}2 \text { with mild paresis and tone change } \\
\text { in the upper limbs. } \\
2 \text { with impaired fine touch }\end{array}$ \\
\hline N8 & 4 & 40 & 0 & 1 & 0 & 0 & 4 & 4 & 4 & $\begin{array}{l}1 \text { ? } \\
\text { vascular } \\
\text { dementia }\end{array}$ & All have impairment of joint position \\
\hline
\end{tabular}


walking stick and one family member, symptomatic for 47 years, used a wheelchair. Rate of disease progression was variable, though was generally slow. Bladder involvement was present in three subjects, with one requiring an indwelling catheter, and five family members suffered from constipation. Typical signs of lower limb spastic paraparesis were found in all affected subjects. Four family members had upper limb hyperreflexia, five subjects had pes cavus, and two had mild distal lower limb amyotrophy. Five family members had decreased lower limb vibration sensation and two had diminished lower limb pain sensation. No overt cognitive impairment was reported in any family member. Three family members also suffered from choroideremia, which was segregating in the family independently of HSP.

\section{N36}

Only one member of this three generation family was seen, and the onset of his disease was at 40 years. The condition has been slowly progressive and 12 years later he remains ambulant. Clinical examination is consistent with a pure HSP phenotype, with some minor distal wasting and sensory loss to pinprick and vibration in his lower limbs. Neuropsychometric testing showed a mild impairment of verbal learning. Complicating his assessment is a history of polio and TB meningitis as a child. His mother, who was presumed from history to be affected with HSP, had a late onset dementia, as did a maternal aunt.

C7

Six affected family members from two generations of this family were seen. Age at onset for symptomatic patients ranged from 2 to 37 years, and one affected subject was asymptomatic at 22 years. One family member used walking sticks and two, both symptomatic for more than 20 years, used a wheelchair. Rate of disease progression was variable, though tended to be slow. Three family members had bladder involvement. Five family members had upper limb hyperreflexia and lower limb examination findings typical of spastic paraparesis were present in all cases. Two patients had foot deformity and one had diminished lower limb vibration and joint position sensation. None of the subjects was reported to have cognitive impairment.

C22

Five affected family members from two generations of this family were examined. Age at onset for symptomatic patients ranged from 2 to 30 years, and one affected subject was asymptomatic at 23 years. One family member required a walking stick although none required a wheelchair. Three family members had bladder involvement and one complained of constipation. Rate of disease progression tended to be slow, though was variable. Typical clinical examination findings of spastic paraparesis were present in all cases. One family member had upper limb hyperreflexia, three subjects had pes cavus, and three subjects had altered fine touch, vibration, or joint position sensation. Cognitive impairment was not reported in any family members.

\section{N37}

This patient is the only known case of HSP in his family. Disease onset was at 11 years and has been very slowly progressive. The only signs of disease in the upper limbs are brisk tendon reflexes. In the lower limbs, he has mild distal impairment of temperature and vibration sensation. He has mood problems, but no other associated features.

\section{C25}

Twelve affected members from three generations of this family were examined. Age at onset of symptoms ranged from 16 to 41 years, and one subject with signs on examination was asymptomatic at 30 years. Four of the family members required a walking stick and five, all symptomatic for at least 30 years, required a wheelchair. Five patients had bladder involvement, one patient suffered from constipation, and another from faecal urgency. Rate of disease progression was variable, but generally slow. Two patients had mild upper limb hyperreflexia, in one accompanied by slight upper limb weakness. In all cases there were typical signs of spastic paraparesis in the lower limbs. Six patients had pes cavus and three pes planus. Mild to moderate lower limb amyotrophy was present in three cases. Seven patients had lower limb sensory abnormalities, involving fine touch, pinprick sensation, or joint position sense. One affected family member aged 80 had a late onset dementia, although further clinical details regarding this are not available.

\section{N8}

Two clinically affected family members were seen. One 70 year old gene carrier is asymptomatic. Both affected family members had disease onset at 40 years, and one requires a wheelchair many years later. All subjects have distal muscle wasting and pes cavus. No bladder involvement was reported. In an 86 year old affected family member, there has been a four year history of progressive dementia with mild word finding difficulties and frontal lobe release signs on the right. Whether or not this relates to a complication of her HSP or is related to another coincidental disease process has not been established with certainty.

\section{GENETIC ANALYSIS}

Using SSCP analysis we identified 13 novel mutations in the SPG4 gene. None of these mutations was present in a control panel of 100 normal chromosomes. Only one of these mutations $(859 \mathrm{C}>\mathrm{G})$ was present in more than one of our families. The two families N4 and N5 were not known to be related, but as both families originate from the same area of England and have the same haplotype for markers D2S2203 and D2S2347 either side of the SPG4 gene, the most probable explanation is that both families share a common ancestor. 
Two mutations $1298+1 \mathrm{~g}>\mathrm{a}$ and $1538+3 \mathrm{del}$ (aagt) have been described previously by Fonknechten et $a l^{20}$ and the remaining mutations are novel.

The majority of mutations (7/13) are splice mutations, all of which affect the donor splice site. These mutations would be expected to result in exon skipping of the preceding exon and would cause a frameshift in the remaining sequence, except in the case of the mutation involving exon 8 (patient N3). All of these mutations would result in severe disruption of the conserved AAA motif.

Three mutations $(859 \mathrm{C}>\mathrm{G}, 411 \mathrm{delG}$, and 1406delT) lead directly or indirectly to a premature stop codon and would result in the production of a truncated protein.

The two missense mutations which behave in a dominant manner are both located in the conserved AAA cassette region and both affect amino acids that are highly conserved between spastin and closely related proteins. ${ }^{19}$ The mutation in family $\mathrm{N} 2$ replaces arginine, a basic amino acid with glycine, which is much smaller and neutral. The mutation in N8 replaces aspartic acid, an acidic amino acid with histidine, a basic amino acid with an aromatic side chain. It seems likely that these changes would severely reduce or abolish the function of the protein. There is little to distinguish these patients phenotypically from those with nonsense/splice mutations. The age of onset is late (40) in family N8, but as can be seen from table 2, the general age of onset in these families is very variable even within a family. In each of the families N2 and N8, an older member was described with dementia, though these were single subjects in each family only.

Patient N35 was homozygous (fig 1) for the mutation in exon 1 which replaces a serine (a polar amino acid) at position 44 with a leucine, a non-polar amino acid. The finding of the homozygous change was confirmed using a different set of primers, this time totally exonic. Repeat sequencing of this product produced the same result. This patient's parents were dead, but neither had shown any symptoms of spastic paraplegia in their lifetime. The patient's sibs, children, and grandchildren were also reported to be disease free. The patient's parents were not known to be consanguineous, but the most likely explanation is that each allele came from the same founder. Haplotype analysis of the flanking markers showed that the two nearest markers, D2S2203 and D2S2351 on the telomeric side of the spastin gene, were homozygous as expected, whereas the nearest markers on the centromeric side, D2S2325 and D2S2347, were heterozygous. These latter markers are, however, further away from the spastin gene on the physical $\mathrm{map}^{24}$ and recombinants between these markers and the spastin gene have previously been noted. This patient was from the north east of England, as were the 100 control chromosomes used to check for the presence of this mutation in the non-HSP population. No other samples were found to have this change, so we believe that this is likely to be a disease associated sequence
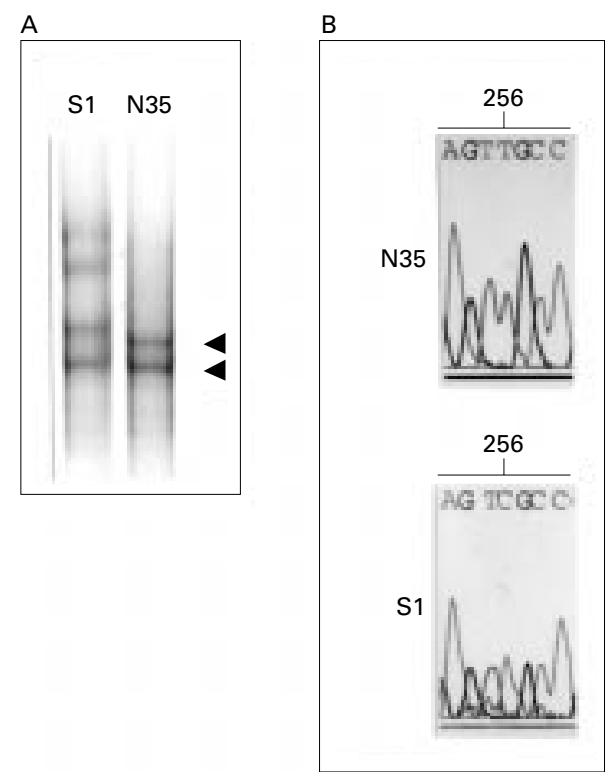

Figure 1 SSCP and sequence analysis of patient N35. (A) Exon 1 a PCR products from N35 and normal DNA sample S1 following electrophoresis on a polyacrylamide gel (silver stained). Note the presence of abnormal and absence of normal bands in patient N35. (B) Partial direct sequence of the exon 1 a PCR product for N35 and a control sample S1, showing that N35 is homozygous for $T$ at position 256.

alteration acting in a recessive manner. Fonknechten et $a l^{20}$ also found no polymorphisms in any exons of the spastin gene in 142 subjects analysed.

\section{Discussion}

Molecular analysis of the gene for spastin in this panel of British HSP patients has shown 13 mutations, 11 of them novel. Each family tested (with the exception of two families probably originating from a common ancestor) had a different mutation. This confirms that mutation detection in this gene in patients with spastic paraplegia will be a more difficult task than if a smaller number of recurrent mutations had been identified. ${ }^{19}$ Further complicating this task, we have evidence that not all SPG4 mutations may be detected using these routine mutation detection techniques, as mutations were not found in three families where linkage to the SPG4 locus had been shown. This incomplete yield of mutations even in families known to be linked to the SPG4 locus was also reported by Fonknechten et al. ${ }^{23}$ In our study, this may reflect the limitations of SSCP which routinely detects only approximately $80 \%$ of mutations. Alternatively, it may mean that sequence outside the coding region needs to be studied, such as the promoter or polyadenylation site. A further possibility, especially as so many of the mutations described so far affect splicing, could be that sequence changes in the introns not detected using these sets of primers might cause disease by activating an intronic cryptic splice site. It is not yet known if alternatively spliced forms of spastin exist, which might potentially contain additional exon sequence, as the RNA transcripts have not been visualised 
by Northern blotting, owing to its low abundance. ${ }^{19}$ In an independent study predating the involvement of this gene in HSP, the spastin cDNA was isolated from brain by Kikuno et $a l^{25}$ and the protein named KIAA1083. This cDNA transcript lacks exon 4 , so it is possible that further splice variants remain to be characterised.

The number of different mutations found, together with the low yield of mutations in the small families and sporadic cases studied, also suggest that mutation detection in spastin may not by itself be a logical way forward for molecular diagnosis in HSP for some time. In addition, the clinical features described in these families with spastin mutations do not provide many useful clues for detecting clinically which patients to target for spastin mutation analysis. HSP has been traditionally classified into "pure" and "complicated" forms depending on whether spasticity is the only feature or whether there are other symptoms, such as epilepsy, dementia, or ataxia. ${ }^{26}$ Most families with a mutation in spastin had a pure HSP phenotype, with remarkable variation in age at onset and severity of the disease, though overall relatively mild disease was the norm. Of 66 affected subjects examined or known of in these families, only 18 required a wheelchair, most late in the course of their disease. Minor signs only (brisk reflexes) were usually found in the upper limbs, with sensory changes detected in the lower limbs in a minority of patients. Bladder involvement was variable. The significance of reports of cognitive decline, mood problems, or affective disorders in occasional family members is difficult to assess; the history of late onset dementia in family $\mathrm{N} 2$ is clearer, and corresponds to previous reports of cognitive problems in SPG4 families. Overall, however, in keeping with previous linkage based reports, ${ }^{21}$ it is hard to discern specific features that would lead to clinical suspicion of spastin involvement in a single case.

The majority of mutations detected so far in SPG4 are predicted to result in either a truncated protein or a severely altered protein, confirming that haploinsufficiency is the cause of the abnormal phenotype. Splice site mutations account for seven out of 13 mutations that we found and this high frequency of splice site mutations is also reported by Fonknechten et $a l^{20}$ The two dominant missense mutations we report affect amino acids in the conserved AAA domain in common with the 11 missense mutations described by Fonknechten et al, ${ }^{20}$ suggesting that this region is crucial for protein function.

The missense mutation in exon 1 , which is outside the conserved AAA motif, is present homozygously in the patient we studied. This patient has no affected relatives with HSP. Clinically, he has very mild disease with late onset. This sequence change was not present in our control population; unfortunately no other members of this family were available for study. Providing that this is not a rare polymorphism with the clinical manifestation of HSP in this person having an alternative cause, this is the first recessive mutation in spastin to be described. Autosomal recessive HSP (ARHSP) is rare and consanguineous families linked to chromosomes 8q, 16q, and 15q have been described, ${ }^{12-14}$ but so far no families with linkage to the SPG4 locus. This mutation, which replaces a serine with a leucine residue at position 44 , is in the early part of the protein, a region which shows little conservation between spastin and related proteins. ${ }^{19}$ In fact, in the closely related yeast protein SAP1, there is a leucine at this position. The most likely hypothesis is that this mutation is behaving as a hypomorph, an allele which produces a reduced amount or activity of product. If this mutation is only on one allele, the amount of spastin is not reduced enough to cause symptoms, but subjects with two copies of the mutant allele have insufficient spastin. The possibility that a "threshold effect" for spastin levels may be critical has already been suggested. ${ }^{23}$ If these conjectures are correct, this would represent an unusual explanation of the dominant and recessive effects of different mutations in the same gene. This hypothesis was recently also postulated to explain dominant and recessive mutations in the connexin 31 gen $^{27}$ (a gene causing non-syndromic hearing loss), although as both dominant and recessive mutations in this gene were missense it was not clear whether the dominant mutations caused the disease through haploinsufficiency or dominant negative effects. If the latter is the case then the recessive mutations in this gene are likely to be null mutations. The discovery of an apparently recessive mutation in SPG4 means that this protein should potentially be considered in patients with ARHSP as well as dominant disease. It will be interesting to see if other recessive mutations are discovered and if these map to the early part of the gene. Such mutations may provide important clues to the function of the spastic protein.

The first two authors contributed equally to this work. The HSP work in Newcastle upon Tyne has been supported by the British Medical Association and the Wellcome Trust. ER is a Wellcome Trust Research Training fellow and is supported by a Sackler award. DCR is a Glaxo Wellcome Fellow. Collection of some patient samples was funded by the UK Medical Research Council.

1 Harding AE. Hereditary spastic paraplegias. Semin Neurol 1993;13:33-336.

2 McKusick VA. Spastic paraplegia, hereditary. In: Mendelian inheritance in man. Baltimore: John Hopkins University Press, 1988:1189.

3 McDermott CJ, White KD, Bushby K, Shaw PJ. Hereditary spastic paraparesis: a review of new developments. F Neurol Neurosurg Psychiatry (in press).

4 Saugier-Veber P, Munnich A, Bonneau D, Rozet JM, Le Merrer M, Cil R, Boespflug-Talguy O. X-linked spastic paraplegia and Pelizaeus-Merzbacher disease are allelic disorders at the proteolipid protein locus. Nat Genet 1994; disorders at

5 Jouet M, Rosenthal A, Armstrong G, MacFarlane J Stevenson R, Paterson J, Metzenberg A, lonasescu V, Temple K, Kenwick S. X-linked spastic paraplegia (SPG1), MASA syndrome and $\mathrm{X}$-linked hydrocephalus due to mutations in one single gene, L1. Eur F Hum Genet 1995;3:273-84.

6 Hazan J, Fontaine B, Bruyn RPM, Larry C, van Deutekom JC, Rime CS, Duirr A, Melki J, Lyon-Caen O, Agid Y. Linkage of a new locus for autosomal dominant familial spastic paraplegia to chromosome 2p. Hum Mol Genet 1994;3:1569-73.

7 Hazan J, Lamy C, Melki J, Munnich A, de Recondo J, Weissenbach J. Autosomal dominant familial spastic paraplegia is genetically heterogenous and one locus maps to chromosome 14q. Nat Genet 1993;5:163-7.

8 Fink JK, Wu CT, Jones SM, Sharp GB, Lange BM, Lesicki Fink JK, Wu CT, Jones SM, Sharp GB, Lange BM, Lesicki
A, Reinglass T, Varvil T, Otterud B, Leppert M. Autosomal dominant familial spastic paraplegia: tight linkage to chromosome 15q. Am f Hum Genet. 1995;56:188-92. 
9 Hedera P, Rainer S, Alvarado D, Zhao X, Williamson I, Otterud B, Leppert M, Fink JK. Novel locus for autosomal
dominant hereditary spastic paraplegia on chromosome dominant hereditary spastic
8q. Neurology 1999;53:44-50.

10 Seri M, Cusano R, Forabosco P, Cinti R, Carol F, Picco P, Bini R, Morra VB, De Michele G, Lerone M, Silengo $M$, Pela I, Borrone C, Romeo G, Devoto M. Genetic mapping to $10 \mathrm{q} 23.3-\mathrm{q} 24.2$, in a large Italian pedigree, of a new syndrome showing bilateral cataracts, gastroesophageal reflux, and spastic paraparesis with amyotrophy. Am $\mathcal{F}$ Hum Genet 1999;64:586-93.

11 Reid E, Dearlove AM, Rhodes M, Rubinsztein DC. A new locus for autosomal dominant 'pure' hereditary spastic paraplegia mapping to chromosome $12 \mathrm{q} 13$, and evidence for further genetic heterogeneity. Am $\mathcal{f}$ Hum Genet 1999;65:773-8.

12 Hentati A, Pericak-Vance MA, Hung WY, Belal S, Laing N Boustany RM, Hentati F, Ben Hamida $M$, Siddique T. Linkage of 'pure' autosomal recessive familial spastic paraplegia to chromosome 8 markers and evidence of genetic plegia to chromosome 8 markers and evidence of genc

13 De Michele G, De Fusco M, Cavalcanti F, Filla A, Marcon $\mathrm{R}$, Volpe G, Monticelli A, Ballabio A, Casari G, Cocozza S. A new locus for autosomal recessive hereditary spastic paraplegia map

14 Martinez Murillo F, Kobayashi H, Pegoraro E, Galluzzi G, Creel G, Mariani C, Farina E, Ricci E, Alfonso G, Pauli RM, Hoffman EP. Genetic localization of a new locus fo recessive familial spastic paraparesis to $15 \mathrm{q} 13-15$. Neurology 1999;53:50-6.

15 Fontaine B, Davoine CS, Durr A, Paternotte C, Feki 1, Weissenbach J, Hazan J, Brice A. A new locus for autosomal dominant pure spastic paraplegia

16 Reid E, Dearlove AM, Osborn O, Rogers MT, Rubinsztein DC. A locus for autosomal dominant pure hereditary spastic paraplegia maps to chromosome $19 \mathrm{q} 13$. Am f $\mathrm{Hum}$ Genet (in press).

17 Casari G, De Fusco M, Ciarmatori S, Zeviani M, Mora M, Fernandez P, de Michele G, Filla A, Cocozza S, Marconi R, Durr A, Fontaine B, Ballabio A. Spastic paraplegia and OXPHOS impairment caused by mutations in paraplegin a nuclear-encoded mitochondrial metalloprotease. Cell

18 Patel S, Latterich M. The AAA team; related ATPases with diverse functions. Trends Cell Biol 1998;8:65-71.
19 Hazan J, Fonknechten N, Mavel D, Paternotte C, Samson D, Artiguenave F, Davoine CS, Cruaud C, Durr A, Prod'h Prod'homme JF, Brice A, Fontaine B, Heilig B, Weisennbach J. Spastin, a novel AAA protein, is altered in the most frequent form of autosomal dominant spastic paraplegia. Nat Genet 1999;23:296-303.

20 Fonknechten N, Mavel D, Byrne P, Davoine CS, Cruaud C, Boentsch D, Samson D, Coutinho P, Hutchinson M, McMonagle P, Burgunder JM, Tartaglione A, Heinzlef O, Feki I, Deufel T, Parfrey N, Brice A, Fontaine B, Prud'homme J-F, Weissenbach J, Durr A, Hazan J.
Spectrum of SPG4 mutations in autosomal dominant spastic paraplegia. Hum Mol Genet 2000;9:637-44.

21 Fink JK, Heiman-Patterson T, Bird T, Cambi F, Dube MP, Figlewicz DA, Fink JK, Haines JL, Heiman-Patterson T, Hentati A, Pericak-Vance MA, Raskind W, Rouleau GA, Siddique T. Hereditary spastic paraplegia: advances in genetic research. Neurology 1996;46:1507-14.

22 Reid E, Grayson C, AM, Rogers MT, Rubinsztein DC. Locus-phenotype correlations in autosomal dominant pure hereditary spastic paraplegia: a clinical and molecular genetic study of 28 United Kingdom families. Brain 1999; 122:1741-55

23 White KD, Ince PG, Lusher M, Lindsey J, Cookson M, Bashir R, Shaw PJ, Bushby KMD. Clinical and pathological findings in hereditary spastic paraparesis with spastin mutation. Neurology (in press).

24 Kikuno R, Nagase T, Ishikawa K, Hirosawa M, Miyajima N, Tanaka A, Kotani H, Nomura N, Ohara O. Prediction of the coding sequences of unidentified human genes. XIV. The complete sequences of 100 new cDNA clones from brain which code for large proteins in vitro. DNA Res 1999; 6:197-205.

25 Harding AE. Classification of the hereditary ataxias and paraplegias. Lancet 1983;i:1151-5.

26 Liu X, Xia XJ, Xu LR, Pandya A, Liang CY, Blanton SH, Brown SD, Steel KP, Nance WE. Mutations in connexin31 underlie recessive as well as dominant non-syndromic underlie recessive as well as dominant
hearing loss. Hum Mol Genet 2000;9:63-7.

27 Hazan J, Davoine CS, Mavel D, Fonknechten N, Paternotte C, Fizames C, Cruaud C, Samson D, Muselet D, Vega-Czarny N, Brice A, Gyapay G, Heilig R, Fontaine B, Weissenbach J. A fine integrated map of the SPG4 locus excludes an expanded CAG repeat in chromosome 2 p-linked autosomal dominant spastic paraplegia. Genomics 1999;60:309-319- 